\title{
COMMITTEE
}

\section{Steering Committee}

Ir. Saut P. Hutagalung, M.Sc

Prof. Dr. Indra Jaya

Prof. Dr. Hari Eko Irianto

Prof. Toshiaki Ohshima

\section{Scientific Committee}

Dr. Ruddy Suwandi

Dr. Maman Hermawan

Prof. Sukoso

Prof. Dr. Linawati Hardjito

Prof. Fredrik Riewpassa

Dr. Aef Permadi

Dr. Eddy Afrianto

Dr. Amir Husni

Dr. Tri Winarni Agustini

Dr. Singgih Wibowo, M.Sc

Dr. Alimuddin

Dr. Sugeng Hari Wisudo

\section{Orginizing Commitee}

Chairman

Chairman I

Chairman II

Secretary I

Secretary II

Treasurer I

Treasurer II

Secretariat
: Dr. Syafril Fauzi, M.Sc

: Dr. Wini Trilaksani, M.Sc

: Dr. Santoso, M.Phil

: Prof. Dr. Joko Santoso

: Ateng Supriatna, M.Sc

: Dr. Ir. Iriani Setyaningsih

: Erwin Dwiyana, M.Sc

: Prof. Dr. Nurjanah

Dr. Desniar

Dr. Mala Nurilmala

Syamdidi, M.Sc

Ir. Theresia Istihastuti, M.Si

Dioko Santoso, S.Pi

Wahyu Ramadhan, M.Si

Toni Rudi Hartanto 


\begin{tabular}{|c|c|}
\hline \multirow[t]{6}{*}{ Program } & : Dr. Bustami Ibrahim, M.Sc \\
\hline & Farida Ariyani, M.Sc \\
\hline & Dr. Kustiariyah Tarman \\
\hline & Dina Fransiska, M.Si \\
\hline & Lia Sugihartini, M.Sc \\
\hline & Ir. Artati Widiarti, MA \\
\hline \multirow[t]{5}{*}{ Paper } & : Dr. Tati Nurhayati \\
\hline & Dr. Emma Hastarini \\
\hline & Dr. Simson Masengi \\
\hline & Ir. Sugiyono, M.Si \\
\hline & Susi Lestari, S.Pi, M.Si \\
\hline \multirow[t]{5}{*}{ Accommodation } & : Dr. Pipih Suptijah \\
\hline & Agustina Pujiastuti, M.Si \\
\hline & Dr. Sri Purwaningsih \\
\hline & Dra. Ella Salamah \\
\hline & Ir. Evi Liviawaty, MS \\
\hline \multirow[t]{2}{*}{ Logistic } & : Dr.Eng. Uju \\
\hline & : M. Darmawan, MT \\
\hline \multirow[t]{4}{*}{ Publication and Documentation } & : Bambang Riyanto, M.Si \\
\hline & Dr. Agoes MJ \\
\hline & Puguh Aji \\
\hline & Samsi Haryono, A.Md \\
\hline \multirow[t]{7}{*}{ Side Event } & : Dr. Sugeng Heri Suseno \\
\hline & Innes Rahmania, A.Pi, MM \\
\hline & Dra. Prihastini N. Lestari, MM \\
\hline & Damar Sugianto, SE, MM \\
\hline & Ir. Widya Rusyanto, M.Si \\
\hline & Widarto, A.Pi, MM \\
\hline & Adityo Nugroho, S.Pi \\
\hline
\end{tabular}

ISSN 2413-0877 @ 2015 The Authors.

Published by KnowledgeE Publishing Services. This is an open access article under the CC BY-NC-ND license (http://creativecommons.org/licenses/by-nc-nd/4.0)

Selection and peer-review under responsibility of the 1st ISAPPROSH 2013 